\title{
Drawdown Farming and Pesticide Residue Levels of the Afram River in Ghana
}

\author{
Koranteng Samuel Senyo ${ }^{1, *}$, Ameka Gabriel Komla², Owusu Ebenezer Oduro ${ }^{3}$ \\ ${ }^{1}$ Institute for Environment and Sanitation Studies (IESS), University of Ghana, Legon, Accra, Ghana \\ ${ }^{2}$ Department of Plant and Environmental Biology, University of Ghana, Legon, Accra, Ghana \\ ${ }^{3}$ Department of Animal Biology and Conservation Science, University of Ghana, Legon, Accra, Ghana
}

Email address:

skoranteng@ug.edu.gh (S. S. Koranteng),gameka@ug.edu.gh (G. K. Ameka), eoowusu@ug.edu.gh (E. O. Owusu)

${ }^{*}$ Corresponding author

\section{To cite this article:}

Koranteng Samuel Senyo, Ameka Gabriel Komla, Owusu Ebenezer Oduro. Drawdown Farming and Pesticide Residue Levels of the Afram River in Ghana. International Journal of Environmental Monitoring and Analysis. Vol. 4, No. 3, 2016, pp. 102-109. doi: 10.11648/j.ijema.20160403.16

Received: May 6, 2016; Accepted: May 16, 2016; Published: May 30, 2016

\begin{abstract}
Cultivation of fruits and vegetables in the drawdown areas (floodplains) of the Afram River relies on pesticides input for enhanced productivity. Application of pesticides in the floodplains can elevate its level in the water and have health implications. Pesticides content of the Afram River at normal level (recess regime) was compared with the flood regime to determine if farming in the drawdown areas has any impact on water quality. Water samples were taken twice during each regime over two consecutive years and pesticide residues were analysed by gas chromatography. The flood periods registered 14 organochlorines, 12 organophosphates and 9 pyrethroids, with respective mean concentration ranges: $0.01-16.79,0.01-$ $2.14,0.01-1.12 \mu \mathrm{g} / \mathrm{L}$; as against 10 organochlorines, 11 organophosphates and 4 pyrethroids quantified during the recess regimes, with respective mean concentration ranges of: $0.01-0.27,0.01-0.37,0.01-0.158 \mu \mathrm{g} / \mathrm{L}$. Levels of 9 pesticides exceeded WHO/EU maximum residue limits for the flood period, in contrast to only 1 during the recess. Dieldrin, endrin, chlorpyrifos and $\beta$-endosulfan exceeded quality criteria limits for the protection of aquatic life during flood regime. Welch two sample t-test on common pesticides quantified during both periods show significantly higher concentrations $(\mathrm{p} \leq 0.05)$ during flood regimes. It is concluded that drawdown farming increases the incidence and concentration of pesticides in water during flood periods and presents health risk to the consuming communities and aquatic life.
\end{abstract}

Keywords: Pesticides, Drawdown, Afram River, Organochlorines, Organophosphates, Pyrethroids

\section{Introduction}

The impoundment of the Volta River created a lake with a surface area of about $8500 \mathrm{~km}^{2}(3.6 \%$ of surface area of Ghana) and a shoreline exceeding $4800 \mathrm{~km} \mathrm{[1].} \mathrm{The}$ impoundment has resulted in periodic flooding of greater part of the upstream shoreline of the lake. Following each flood regime, floodplains, high in moisture content are exposed. Crop production in the floodplains has been identified by the Volta Lake Research and Development Project (VLRDP) as a potential farming opportunity requiring little irrigation effort. Furthermore, the VLRDP identified that cultivation of the exposed flood plains could take place between the months of November and May, when the lake normally recedes and it is optimal for the cultivation of short maturing crops such as okro, onions, pepper, tomatoes garden eggs, etc. The exposed floodplains are referred to as the drawdown areas and the farming activities associated with them called drawdown farming. The drawdown farming was particularly identified to suit the Afram arm of the lake [2] Communities along the Afram arm of the Volta Lake were therefore encouraged to indulge in it and are now noted for this type of farming. Advantage is taken of the residual moisture in the soil hence reducing the burden of irrigation. Later, when the moisture level of the soil falls below the optimum, manual or can irrigation is employed [1]. When water level rises, previously cultivated lands and sometimes lands still under cultivation are inundated. 
Reconnaissance studies revealed that pest infestation confronts cultivation of fruits and vegetables in the drawdown areas. Farmers therefore rely on agrochemicals, including organochlorines and second generation pesticides like pyrethroids, organophosphorus and cabarmates to overcome pest infestation challenges and to improve yields of crops. Reliance on pesticides has implications for water quality and hence, health. It is important and useful to know the implication of occasional flooding of farms and farmlands in the drawdown areas on the pesticide content of water. This is particularly pertinent since water from the river is the only source of potable water for most of the communities situated along the River Afram. The research is also in line with the world-wide interest in quantifying and controlling pollution of surface waters [3]. This work therefore seeks to investigate and compare pesticide residues levels of water of the Afram River at normal water levels (recess regimes) and during flood periods (flood regimes), and to determine the impact of farming in the drawdown areas on water quality.

\section{Materials and Methods}

\subsection{Study Area}

River Afram is a major tributary located at the base of the Volta Lake and lies within the coordinates: N $06^{\circ} 34^{\prime} 124^{\prime \prime}$ $06^{\circ} 43^{\prime} 696^{\prime \prime}$ and $\mathrm{W} 000^{\circ} 14^{\prime} 089^{\prime \prime}-000^{\circ} 37^{\prime} 810^{\prime \prime}$. It is about $220 \mathrm{~km}$ long and the study area lie along its lower reaches, spaning three administrative districts of the Eastern Region (Fanteakwa, Kwahu South and Kwahu East) of Ghana. Water sampling sites were near four communities, namely: Dedeso, Kwahu Amanfrom, Adawso and Kotoso (Fig. 1). In these communities, drawdown farming is a well established small scale industry. Apart from drawdown farming, the people in the study area are actively engaged in commercial irrigation farming of fruits and vegetables all-year long. Their initial mainstay business of fishing has become a supplementary activity due to low yields from fishing expeditions as a result of depleting fish stock. The topography of the area is generally hilly with undulating landforms. The parent rocks are mainly the Birimian formation and Voltaian metamorphosed sediments. The area experiences an average temperature of $24^{\circ} \mathrm{C}$ and a double maxima rainfall during the period of June to October, with just slight deviations, and a mean value between $150 \mathrm{~mm}$ to about $2000 \mathrm{~mm}$.

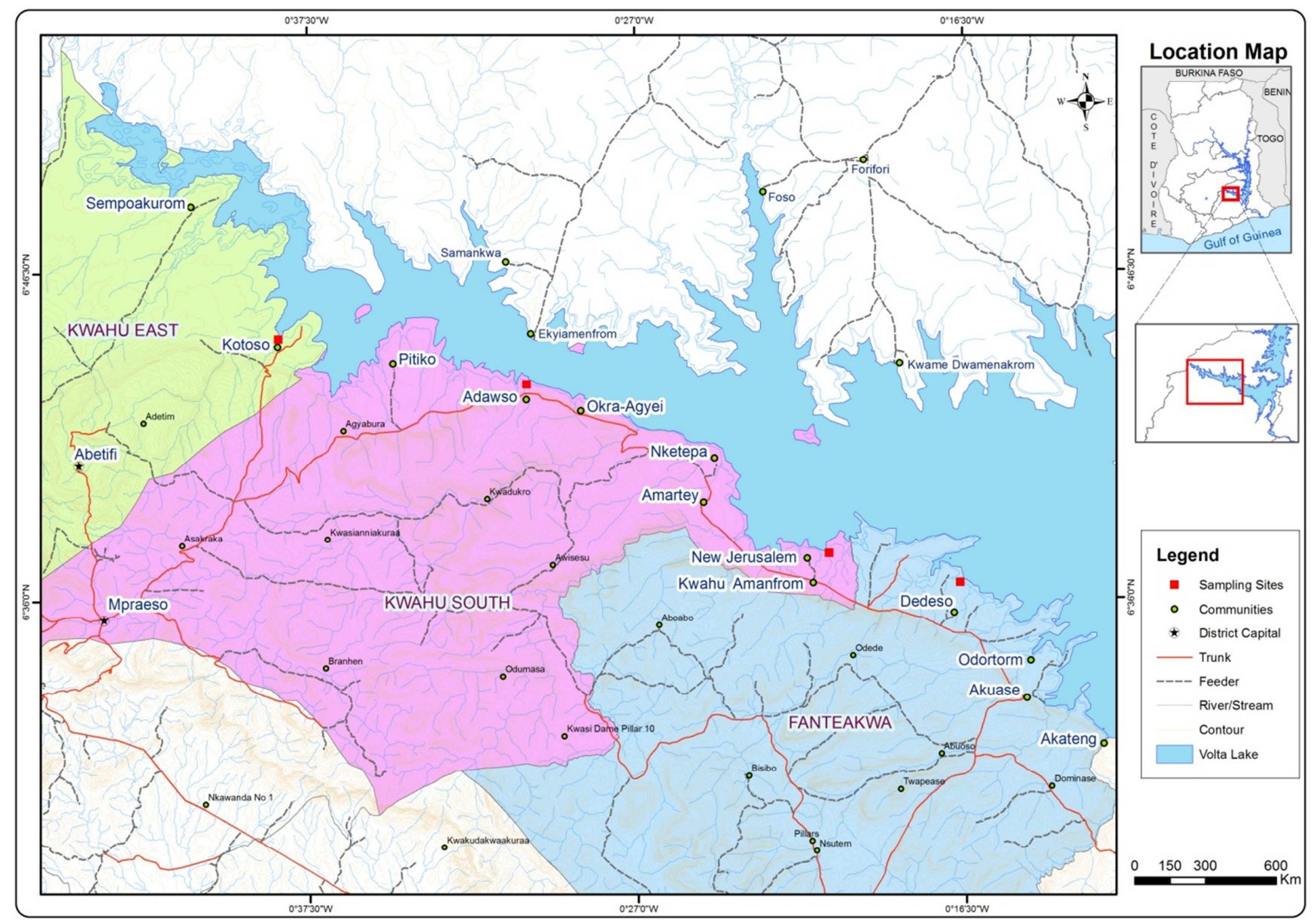

Fig. 1. Map of study area showing sampling sites. 


\subsection{Chemicals and Reagents}

Reagents used in the study comprised: Methylene chloride, Ethyl acetate and Acetone were of purest grade (pesticide grade) and so were anhydrous sodium sulphate and sodium chloride. All these were acquired from BDH laboratory Supplies, England. Silica gell was purchased from Phenomenex (Torrence, CA, USA). The individual pesticides reference standards used for the quantification and identification of the pesticides were of high purity (Purity $>$ 99\%) and obtained from Dr. Ehrenstofer GmBH (Augsburg, Germany) for the following pesticides that were analysed: Organochlorines; $\alpha$-Lindane, $\beta$ - Lindane, $\gamma$ - Lindane, $\delta$ lindane, aldrin, heptachlor, $\gamma$-chlordane, $\alpha$-endosulfan, $p, p$ 'DDE, dieldrin, endrin, $\beta$-endosulfan, $p, p^{\prime}-D D T, p, p$ '$D D D, \quad$ Endosulfan-sulfate and Methoxychlor; organophosphorus: Methamidophos, Ethoprophos, Phorate, Diazinon, Fonofos, Dimethoate, Pirimiphos-methyl, Chlorpyrifos, Malathion, Fenitrothion, Parathion, Chlorfenvinphos, Profenofos and synthetic pyrethroids: Allethrin, Bifenthrin, Fenpropathrin, Lamda-cyhalothrin, Permethrin, Cyfluthrin, Cypermethrin, Fenvalerate, Deltamethrin.

\subsection{Sampling of Water}

Water samples were collected at four sites of the Afram River (Fig 1) and taken for two consecutive periods for each regime. Flood regime water samples were taken in December 2011 and December -January 2013, while the recess regime water samples were taken during May 2012 and July 2013. At each site, twenty water samples were taken for both regimes. Thus a total of eighty water samples were collected from four sites. Water samples were taken approximately 0.5 $\mathrm{m}$ below the surface at midstream positions to approximate the mean concentrations of water from the river. The samples were taken with a $3 \mathrm{~L}$ Goflon water sampler into $1 \mathrm{~L}$ amber glass bottles that were previously washed with detergent, rinsed with distilled water, dried and finally rinsed with acetone. Prior to sample collection, each bottle was rinsed with the river water three times.

\subsection{Extraction of Water Samples}

Water samples were removed from fridge and allowed to equilibrate with the ambient temperature. The samples were extracted according to [4]. Briefly, water samples were well shaken and filtered through whatman filter paper no.1. After filtration, 1 litre water sample was taken into a 2 litre capacity separatory funnel and $30 \mathrm{~mL}$ of saturated sodium chloride solution was added. The water sample was partitioned with $100 \mathrm{~mL}$ of methylene chloride by shaking the separatory funnel vigorously for 2-3 minutes and releasing the pressure intermittently. The layers were allowed to stand for 10 minutes to separate. The organic layer was drained into $250 \mathrm{~mL}$ conical flask while the aqueous phase was re-extracted twice with 100 $\mathrm{mL}$ methylene chloride. The extracted organic phase was combined and dried by passing through anhydrous sodium sulphate in a glass funnel and subsequently concentrated to about $1 \mathrm{~mL}$ using rotary vacuum evaporator. One litre of deionized water was taken as a procedural blank and similarly extracted. The concentrated extracts were then cleaned-up as described below.

\subsection{Sample Clean-up}

Clean-up of the extracted samples was done by column chromatography. Ten mililitres polypropylene cartridge was packed with $2 \mathrm{~g}$ activated silica gel (previously conditioned by heating at $130^{\circ} \mathrm{C}$ for $2 \mathrm{~h}$ ). The silica gel was sandwiched between two layers, each of $1 \mathrm{~g}$ sodium sulphate and the entire column was conditioned with $10 \mathrm{~mL}$ of methylene chloride and not allowed to dry. The $1 \mathrm{~mL}$ concentrate from the extraction was then loaded onto the conditioned cartridges by rinsing the flask with two portions of $5 \mathrm{ml}$ methylene chloride and allowing the column to elute into a pear-shaped flask. The elution was repeated with another 10 $\mathrm{ml}$ portion of methylene chloride. The combined eluate was collected and evaporated to just dryness using rotary vacuum evaporator. The final extract was re-dissolved in $1 \mathrm{~mL}$ of ethyl acetate (HPLC grade) and transferred into a $1.5 \mathrm{~mL}$ standard opening vial for quantitation with GC-ECD and GC-PFPD.

\subsection{Instrumental Analysis}

Organochlorines and synthetic pyrethroid pesticides in the final pesticide extracts were analyzed by Gas ChromatographVarian CP-3800 (Varian Association Inc. USA) equipped with combiPal autosampler and ${ }^{63} \mathrm{Ni}$ electron capture detector (ECD). The GC conditions used for the analysis were capillary column coated with VF-5 $(30 \mathrm{~m}+10 \mathrm{~m}$ guard column $\times 0.25$ $\mathrm{mm}$ i.d, $0.25 \mu \mathrm{m}$ film thickness). The injector and detector temperatures were set at $270^{\circ} \mathrm{C}$ and $300^{\circ} \mathrm{C}$ respectively. The oven temperature was programmed as follows: $70^{\circ} \mathrm{C}$ held for $2 \mathrm{~min}$, ramp at $25^{\circ} \mathrm{Cmin}^{-1}$ to $180^{\circ} \mathrm{C}$, held for $1 \mathrm{~min}$, and finally ramp at $5^{\circ} \mathrm{Cmin}^{-1}$ to $300^{\circ} \mathrm{C}$. Nitrogen was used as carrier gas at a flow rate of $1.0 \mathrm{mLmin}^{-1}$ and detector make-up gas of $29 \mathrm{mLmin}-1$. The injection volume of the GC was $1.0 \mu \mathrm{L}$. The total run time for a sample was $31.4 \mathrm{~min}$.

Organophosphorus pesticides on the other hand were analyzed by Gas Chromatograph- Varian CP-3800 (Varian Association Inc. USA) also equipped with combiPal autosampler and pulse flame photometric detector (PFPD). The GC conditions used for the analysis were capillary column coated with VF-1701 (30 m x $0.25 \mathrm{~mm}$ i.d, $0.25 \mu$ $\mathrm{m}$ film thickness). The injector and detector temperature were set at $270^{\circ} \mathrm{C}$ and $280^{\circ} \mathrm{C}$ respectively. The oven temperature was programmed as follows: $70^{\circ} \mathrm{C}$ held for 2 min, ramp at $25^{\circ} \mathrm{C} \min ^{-1}$ to $200^{\circ} \mathrm{C}$, held for $1 \mathrm{~min}$, and finally ramp at $20^{\circ} \mathrm{C} \mathrm{min}-1$ to $250^{\circ} \mathrm{C}$ maintained for 3.3 min. Nitrogen was used as carrier gas at a flow rate of 2.0 $\mathrm{mLmin}^{-1}$ and detector make-up gases (17.0, 14.0 and 10.0 $\mathrm{mLmin}^{-1}$ ) for hydrogen, air-1 and air-2, respectively. The injection volume of the GC organophosphorus 
pesticide determination was $2.0 \mu \mathrm{L}$. The total run time for a sample was $14 \mathrm{~min}$. Each sample underwent duplicate analyses.

\subsection{Analytical Quality Control}

Recoveries were calculated for three replicate de-ionised water samples spiked with $5 \mathrm{ml}$ of $0.05 \mu \mathrm{g} / \mathrm{L}$ standard mixture solutions of organochlorines, organophosphorus and synthetic pyrethroid pesticides. The percentage recovery ranged between 96 -104. Sample analysis data were therefore not corrected for recoveries. Reagent and procedural blanks were also extracted in the same manner as samples and found to be devoid of any interfering agents and for each batch of 20 samples, a procedural blank, and a pair of spiked blank were processed. Limit of quantification (LOQ) of the method was assessed based on lowest analyte concentration that could consistently and reliably yield $70 \%$ or more recovery from spiked samples and also gave signal:noise ratio of 3 [5]. This lowest concentration was run 10 times and the standard deviation (SD) of the signals calculated. Three times the SD gave the limit of detection (LOD) while 10 times the SD gave the limit of quantification. The LOQ for the pesticides was $0.01 \mu \mathrm{g} / \mathrm{L}$. Recalibration curves were run with each sample batch to ensure that correlation coefficient was not below 0.99. All glasswares were washed with hot water and detergents and copiously rinse with distilled water. After drying, the glass wares were further rinsed with acetone.

\subsection{Data Analysis}

Incidence rates of individual pesticides were determined by their frequencies. Means and concentration ranges were as well calculated. Frequencies of pesticides that were quantified under recess regimes were extremely low in most of the cases. Therefore in determining significant differences in concentrations of pesticides occurring during both regimes, an assumption based on the model of [6] for treatment of non-detect samples was employed; namely: "if a pesticide has not been detected at all in a commodity, then the non-detect samples of that commodity are assumed to be zero. If however, pesticides have been detected in some samples, then the non-detect samples are assumed to be $50 \%$ of the limit of detection". The second half of the assumption was adopted. Because variances for the two data sets were not equal, Welch two sample t-test (using The $\mathrm{R}$ software version 3.1.1) was used to assess significant differences between means of pesticide residues that were registered under both regimes. Possibilities less than $0.05(p<0.05)$ were considered significant. The assumption of normality of errors was assessed using the Shapiro-Wilk test [7].

\section{Results and Discussion}

Details of pesticide content of lake water from the Afram arm of the Volta Lake during both regimes are presented in Table 1. In all, thirty-six pesticide residues were quantified in the water samples. Thirty-five of them were quantified during flood regime and 25 under recess regime. The grand mean concentrations of the OCPs, SPs and OPs during the flood regime were $15.22,1.47$ and $0.91 \mu \mathrm{g} / \mathrm{L}$ respectively as compared to their corresponding values of $0.047,0.127$ and 0.382 during the recess regime. Similarly average frequencies of occurrence were far higher during the flood period, with exception of the OPs, (Table 1). The mean concentration ranges are also indicated.

Table 1. Comparison of pesticide water quality during occasional flooding of farmlands and period of recession (OCPs- organochlorines; SPs- synthetic pyrethroids; OPs- organophosphates).

\begin{tabular}{|c|c|c|c|c|c|c|c|c|c|c|}
\hline \multirow[b]{2}{*}{$\begin{array}{l}\text { Pesticide } \\
\text { group }\end{array}$} & \multicolumn{5}{|l|}{ Flood Regime } & \multicolumn{5}{|c|}{ Recession Regime } \\
\hline & $\begin{array}{l}\text { No. of Pesticides } \\
\text { detected }\end{array}$ & $\begin{array}{l}\mathrm{MC}_{\mathrm{G}} \\
(\mu \mathrm{g} / \mathrm{L})\end{array}$ & $\begin{array}{l}\text { Range } \\
(\mu \mathrm{g} / \mathrm{L})\end{array}$ & $\begin{array}{l}\text { Average } \\
\text { Frequency (\%) }\end{array}$ & MRLe & $\begin{array}{l}\text { No. of } \\
\text { Pesticides } \\
\text { detected }\end{array}$ & $\begin{array}{l}\mathrm{MC}_{\mathrm{G}} \\
(\mu \mathrm{g} / \mathrm{L})\end{array}$ & $\begin{array}{l}\text { Range } \\
(\mu \mathrm{g} / \mathrm{L})\end{array}$ & $\begin{array}{l}\text { Average } \\
\text { Frequency (\%) }\end{array}$ & MRLe \\
\hline OCPs & 14 & 15.22 & $0.01-16.79$ & 89.6 & 5 & 10 & 0.047 & $0.01-0.27$ & 17.5 & 1 \\
\hline SPs & 9 & 1.47 & $0.01-2.14$ & 85 & 3 & 4 & 0.127 & $0.01-0.37$ & 23.8 & 0 \\
\hline OPs & 12 & 0.91 & $0.01-1.12$ & 20 & 1 & 11 & 0.382 & $0.01-0.158$ & 31 & 0 \\
\hline Total & 35 & 17.60 & $0.01-16.79$ & & 9 & 25 & 1.01 & $0.01-0.370$ & & 1 \\
\hline
\end{tabular}

$\mathrm{MC}_{\mathrm{G}}=$ Grand mean concentrations of all residues in a pesticide group

$\mathrm{MRL}_{\mathrm{e}}=$ Number of residues Exceeding WHO MRL

The huge disparity between incidence rate of pesticides between the two regimes is clearly evident, for instance allethrin, bifenthrin, permethrin, deltamethrin, $\beta-\mathrm{HCH}, \gamma-$ $\mathrm{HCH}, \delta-\mathrm{HCH}$, aldrin, endrin, dieldrin, $p, \quad p$-DDD, endosulfan sulfate and methoxychlor, all registered $100 \%$ incidence rate during flood regime; while none recorded $100 \%$ under the recess (Table A1). Similarly, concentration levels of pesticides were higher during the flood period with as many as 9 pesticide residues, $\beta$-lindane, $\delta$-lindane, aldrin, dieldrin, endrin, fenpropathrin, cypermethrin, deltamethrin and methamidophos exceeding their corresponding World health organization (WHO) or European union (EU) maximum residue limits (MRL). For instance $\delta$-lindane, aldrin, dieldrin, endrin and cypermethrin respectively recorded mean concentrations of $6.264,1.031,1.385,1.900$ and $0.637 \mu \mathrm{g} / \mathrm{L}$, exceeding their respective WHO or EU limits as indicated in Table 2. During the recess regime however, only dieldrin, recorded mean residue concentration above acceptable limits. T-test analysis to compare means of 18 residues that were quantified under both regimes revealed that $61 \%$ of the residues concentrations were significantly higher under flood conditions while only dimethoate, representing 5.5\% was higher under recess regime Table 3. 
Table 2. Residue levels of pesticides that exceeded WHO/EU MRL during the two regimes.

\begin{tabular}{llllll}
\hline Flood regime & \multicolumn{3}{c}{ Recess regime } & \multirow{2}{*}{ WHO MRL $(\mu \mathrm{g} / \mathbf{L})$} & EU MRL $(\mu \mathrm{g} / \mathbf{L})$ \\
\hline Pesticide & Mean Conc. $(\mu \mathrm{g} / \mathbf{L})$ & Pesticide & Mean Conc. $(\boldsymbol{\mu g} / \mathbf{L})$ & 1.00 & 0.10 \\
\hline$\beta$-lindane & & & 2.00 & 0.10 \\
$\delta$-lindane & 4.217 & & 0.03 & 0.10 \\
Aldrin & 6.264 & & 0.03 & 0.10 \\
Dieldrin & 1.031 & Dieldrin & 0.084 & 0.60 & 0.10 \\
Endrin & 1.385 & & & - & 0.10 \\
Cypermethrin & 1.900 & & - & 0.10 \\
Fenproathrin & 0.637 & & - & 0.10 \\
Deltamethrin & 0.341 & & - & 0.10 \\
Methamidophos & 0.234 & & & \\
\hline
\end{tabular}

-: Not available

WHO/EU MRL (European Union default drinking water standard for pesticides, 1998-2016) Retrieved

from: http://www.lenntech.com/who-eu-water-standards.htm

Table 3. Welch two sample t-test of means of pesticides concentration in water under flood and recess regimes

\begin{tabular}{lllll}
\hline Pesticides & Mean $(\boldsymbol{\mu g} / \mathbf{L})$ Flood & Mean $(\boldsymbol{\mu g} / \mathbf{L})$ Recession & p-values & Significant Difference \\
\hline Organochlorines & & & & \\
\hline$\gamma$-HCH & 0.0685 & 0.0667 & 0.9199 & No $(\mathrm{p}>0.05)$ \\
$\delta$-HCH & 6.2643 & 0.0022 & $3.869 \times 10^{-9}$ & Yes $(\mathrm{p}<0.05)$ \\
$\mathrm{p}, \mathrm{p}$-DDE & 0.0366 & 0.0044 & $4.375 \times 10^{-10}$ & Yes $(\mathrm{p}<0.05)$ \\
Dieldrin & 1.3854 & 0.0056 & $1.73 \times 10^{-7}$ & Yes $(\mathrm{p}<0.05)$ \\
Endrin & 1.9001 & 0.0031 & $1.185 \times 10^{-15}$ & Yes $(\mathrm{p}<0.05)$ \\
p,p'-DDT & 0.0112 & 0.0273 & 0.0965 & No $(\mathrm{p}>0.05)$ \\
p,p'-DDD & 0.0365 & 0.0015 & $9.295 \times 10^{-14}$ & Yes $(\mathrm{p}<0.05)$ \\
Endosulfan sulfate & 0.0237 & 0.0070 & 0.00355 & Yes $(\mathrm{p}<0.05)$ \\
Methoxychlor & 0.1023 & 0.0019 & $2.291 \times 10^{-5}$ & Yes $(\mathrm{p}<0.05)$ \\
Pyrethroids & & & Yes $(\mathrm{p}<0.05)$ \\
Fenpropathrin & 0.1526 & 0.0032 & $6.549 \times 10^{-8}$ & Yes $(\mathrm{p}<0.05)$ \\
Permethrin & 0.0664 & 0.0022 & $2.3 \times 10^{-7}$ & Yes $(\mathrm{p}<0.05)$ \\
Cypermethrin & 0.0449 & $3.558 \times 10^{-5}$ & \\
Organophosphate & & & & Yes $(\mathrm{p}<0.05)$ \\
Methamidophos & 0.3608 & 0.0431 & $4.201 \times 10^{-5}$ & Yes $(\mathrm{p}<0.05)$ \\
Dimethoate & 0.0067 & 0.0238 & 0.0347 & No $(\mathrm{p}>0.05)$ \\
Pirimiphos-methyl & 0.0017 & 0.0021 & 0.2619 & No $(\mathrm{p}>0.05)$ \\
Chlorpyrifos & 0.0112 & 0.0090 & 0.3202 & No $(\mathrm{p}>0.05)$ \\
Malathion & 0.0043 & 0.0390 & 0.7958 & No $(\mathrm{p}>0.05)$ \\
Fenitrothion & 0.0065 & 0.0062 & 0.8822 & \\
\hline & & & &
\end{tabular}

Vegetables like okra, onion, tomato, pepper and water melon fruits which typically mature within three months are the most cultivated crops in the flood plains. Over the years, pest infestation and persistence has become a major challenge hence reliance on insecticide for improved yields became inevitable. The high incidence and variety of pesticide residues in the water samples underscores the application of a wide range of pesticides in the cultivated fields along the banks of Afram arm of the Volta Lake. Farmers have indicated that recession of water in the lake was previously predictable hence they could plan when to cultivate the drawdown areas and harvest in time before water levels rose. Within the past decade however, periods of flooding are no longer predictable; due to low rainfall and low volume of water from the tributaries of the Afram, obviously due to climate variability. The potential of crop loss before maturity due to flooding has therefore increased the risk associated with drawdown farming. In the event of flooding, residual agrochemicals, including pesticides on farmlands dissolve in the water, invariably causing their levels to be elevated. This primarily explains high incidence and concentration levels of even non-persistent second generation pesticides like pyrethroids and organophosphates. Higher frequency of occurrence and concentration of pesticide residues implies associated higher health risk with water consumption during the flood regime. Unfortunately this is the only source of potable water for most of the communities along the Afram arm of the Volta Lake. Few communities have been provided with boreholes in an attempt to discourage the use of raw water from the river in order to reduce the incidence of water-borne diseases. In such communities, it was observed that individuals still prefer water from the river since majority of them complain about high salt content of borehole water. 
Table 4. Pesticide levels compared with USEPA water quality criteria for the protection of aquatic life.

\begin{tabular}{lllll}
\hline \multirow{2}{*}{ Pesticide } & \multirow{2}{*}{ Mean Flood conc. $(\boldsymbol{\mu g} / \mathbf{L})$} & \multirow{2}{*}{ Mean Recess conc. $(\boldsymbol{\mu g} / \mathbf{L})$} & \multicolumn{2}{l}{ USEPA Quality Criteria $(\boldsymbol{\mu g} / \mathbf{L})$} \\
\cline { 4 - 5 } & & & Acute effect conc. & Chronic effect conc. \\
\hline Endrin & 1.900 & 0.084 & 0.086 & 0.0360 \\
Dieldrin & 1.385 & & 0.240 & 0.0560 \\
B-endosulfan & 0.590 & & 0.220 & 0.0560 \\
Chlorpyrifos & 0.160 & & 0.083 & 0.0410 \\
Heptachlor & 0.011 & 0.035 & 0.520 & 0.0038 \\
$p, p$ '-DDT & 0.066 & 1.000 & 0.0010 \\
\hline
\end{tabular}

Comparison of pesticide residue level of the two regimes with [8] water quality criteria for protection of aquatic life also shows aquatic fauna are likely to suffer from acute toxic effects of 4 pesticide residues (endrin, dieldrin, $\beta$-endosulfan and chlorpyrifos) during the flood regimes since they exceeded the quality criteria limits (Table 4.) In contrast, recess regime recorded the residue of only two (dieldrin and $p, p$ '-DDT) whose exposure could have chronic toxic effects.

The recess regime typifies the normal water level in the River Afram since flooding in the past decade has become occasional events. Results for the recess period thus reflect levels of contaminants that are likely to be accessed during routine determinations. The current study, when compared with values from studies conducted on other water bodies with agricultural activities along them generally indicates that whereas the recess concentration levels of OCP pesticides in the river Afram are lower, those of the flood regimes are higher (Table 5). This is true both for local studies by [9-13] as well as for studies from other regions carried out by [14-17]. However, OCP residues from Densu River [18] in Ghana were about 3 folds higher than the flood concentration from the current studies. Similarly, [19] and [20] recorded astronomical levels of pesticide residues in water samples from Lake Naivasha in Kenya and Benue River in Nigeria respectively (Table 5).

Table 5. Level of pesticides in current study compared with other studies (local and international).

\begin{tabular}{|c|c|c|c|c|}
\hline Reference & Pesticides & Location & Conc. range $(\mu \mathrm{g} / \mathrm{L})$ & \\
\hline \multicolumn{5}{|l|}{ Local studies } \\
\hline Ntow (2005) & 6 OCPs & Lake Volta & $0.008-0.036$ & \\
\hline Darko et al., (2008) & 6 OCPs & Lake Bosomtwi & $0.10-1.610$ & \\
\hline Fianko (2011) & 8 OCPs & River Densu & $0.10-48.600$ & \\
\hline Kuranchie-Mensah et al., (2012) & 14 Ocps & River Densu & $0.01-1.070$ & \\
\hline Agyapong et al., (2013) & 12 OCPs & River Tano & $0.008-0.958$ & \\
\hline Afful et al., (2013a) & 12 OCPs & Lake Bosomtwi & $0.01-6.350$ & \\
\hline Afful et al., (2013b) & 9 SPs & Weija - Densu & $0.10-3.500$ & \\
\hline Fosu-Mensah, et al., (2016) & 4 SPs & Surface wells in some cocoa-growing areas in Ghana & $<0.01-0.07$ & \\
\hline \multicolumn{5}{|l|}{ Studies from other regions } \\
\hline Ize-Iyamu et al., (2007) & 7 OCPs & 3 rivers in Edo State-Nigeria & $0.287-0.814$ & \\
\hline Mwevura et al., (2002) & 4 OCPs & 2 rivers in Dar es-Salaam - Tanzania & $0.05-2.500$ & \\
\hline Gitahi (1999) & 6 OCPs & Lake Naivasha - Kenya & $0.50-1595.90$ & \\
\hline \multirow[t]{2}{*}{ Mahdavian and Somashekar (2013) } & 7 OCPs & River Cauvery - India & $1.00-9.00$ & \\
\hline & $2 \mathrm{SPs}$ & " & $0.50-12.00$ & \\
\hline \multirow{3}{*}{ Lari et al., (2014) } & 3 OCPs & Godavari River - India & nd -0.42 & \\
\hline & $4 \mathrm{OPs}$ & " & nd -0.44 & \\
\hline & 6 OCPs & River Benue - Nigeria & $150.00-5240.00$ & \\
\hline \multirow[t]{2}{*}{ Akan et al., (2015) } & 4 SPs & $"$ & $290.00-1520.00$ & \\
\hline & $6 \mathrm{OPs}$ & $"$ & $510.00-810.00$ & \\
\hline \multirow[t]{4}{*}{ Current Study } & & & Flood Regime & Recess Regime \\
\hline & 14 OCPs & River Afram & $0.01-16.790$ & $0.01-0.269$ \\
\hline & 9 SPs & $"$ & $0.01-2.135$ & $0.01-0.370$ \\
\hline & 13 OPs & $"$ & $0.01-1.120$ & $0.01-0.158$ \\
\hline
\end{tabular}

nd - Not detected

The current preponderance of pyrethroids and organophosphorus pesticides in agricultural activities should warrant priority assessment of their residue in fresh water bodies. However, there seems to be general dearth of research in this direction. So far, only [21] and [22] have reported on pyrethroids residue levels in fresh water sources in Ghana. Whereas the reported values of [21] $(0.10-3.50$ $\mu \mathrm{g} / \mathrm{L}$ ) in Weija part of Densu River in Ghana was above that recorded for both flood and recess regimes of the current study $(0.01-2.135,0.01-0.37 \mu \mathrm{g} / \mathrm{L}$ respectively $)$, the concentrations recorded by [22] in a very recent work on pyrethroids residues $(<0.01-0.07 \mu \mathrm{g} / \mathrm{L})$ in surface hand-dug wells in cocoa growing communities were well below values recorded in this study. 


\section{Conclusion}

Pesticide residue concentration levels associated with the flood regime along the Afram arm of the Volta Lake is significantly higher than the recess concentration. The difference is mainly due to contribution by residues in the drawdown farmlands whenever they are flooded. The flood concentrations of pesticides were higher when compared to other studies. The recess regime, which typifies the normal condition, however recorded pesticide residue levels that are generally lower than those from other studies. Drawdown farming along river Afram River therefore increases the incidence and concentration of pesticide residues in the waters during periods of flooding and residue levels are above the WHO and the EU maximum acceptable limits. Consumption of water from the Afram River during the flood regime is thus associated with higher health risk to humans and likely to have acute and chronic toxic effects on aquatic organisms. Wherever farming in the flood-plains (drawdown area) occurs, it must be critically evaluated by the concerned Environmental Protection Agency (EPA) and appropriate policy measures subsequently put in place to reduce pesticide contamination of the fresh water bodies. It is possible, over a period of study time, to identify the highest water mark during flood regimes and then prohibit farming activity below this point. If farming must be done in the drawdown at all, then it must be limited to those crops that do not necessarily require the input of pesticides e.g.: potatoes, cassava, maize.

\section{Appendix}

Table A1. Comparative incidence rates and mean concentrations of pesticides in water samples of flood and recess regimes of the Afram River.

\begin{tabular}{|c|c|c|c|c|}
\hline \multirow[b]{2}{*}{ Pesticides } & \multicolumn{2}{|c|}{ Flood Regime } & \multicolumn{2}{|c|}{ Recess Regime } \\
\hline & $\begin{array}{l}\text { Mean } \\
(\mu \mathrm{g} / \mathrm{L})\end{array}$ & $\begin{array}{l}\text { Frequency } \\
(\%)\end{array}$ & $\begin{array}{l}\text { Mean } \\
(\mu \mathrm{g} / \mathrm{L})\end{array}$ & $\begin{array}{l}\text { Frequency } \\
(\%)\end{array}$ \\
\hline \multicolumn{5}{|l|}{ Organochlorines } \\
\hline$\beta-\mathrm{HCH}$ & 4.217 & 100 & & \\
\hline$\gamma-\mathrm{HCH}$ & 0.065 & 100 & 0.185 & 35 \\
\hline$\delta-\mathrm{HCH}$ & 6.264 & 100 & 0.010 & 25 \\
\hline Heptachlor & 0.011 & 80 & & \\
\hline Aldrin & 1.031 & 100 & & \\
\hline$\alpha$-endosulfan & 0.020 & 75 & 0.010 & 5 \\
\hline $\mathrm{p}, \mathrm{p}^{\prime}-\mathrm{DDE}$ & 0.040 & 90 & 0.060 & 5 \\
\hline Dieldrin & 1.385 & 100 & 0.084 & 5 \\
\hline Endrin & 1.900 & 100 & 0.033 & 5 \\
\hline Beta endosulfan & 0.059 & 95 & & \\
\hline p,p'-DDT & 0.066 & 15 & & 75 \\
\hline p,p'-DDD & 0.036 & 100 & & 5 \\
\hline Endosulfan sulfate & 0.023 & 100 & 0.057 & 10 \\
\hline Methoxychlor & 0.102 & 100 & 0.011 & 5 \\
\hline \multicolumn{5}{|l|}{ Pyrethroids } \\
\hline Allethrin & 0.056 & 100 & & \\
\hline Bifenthrin & 0.051 & 100 & & \\
\hline Fenpropathrin & 0.341 & 85 & 0.036 & 5 \\
\hline Lamda-cyhalothrin & 0.067 & 90 & & \\
\hline Permethrin & 0.066 & 100 & 0.015 & 5 \\
\hline Cyfluthrin & 0.010 & 60 & 0.013 & 15 \\
\hline Cypermethrin & 0.637 & 75 & 0.063 & 70 \\
\hline
\end{tabular}

\begin{tabular}{|c|c|c|c|c|}
\hline \multirow[b]{2}{*}{ Pesticides } & \multicolumn{2}{|c|}{ Flood Regime } & \multicolumn{2}{|c|}{ Recess Regime } \\
\hline & $\begin{array}{l}\text { Mean } \\
(\mu \mathrm{g} / \mathrm{L})\end{array}$ & $\begin{array}{l}\text { Frequency } \\
(\%)\end{array}$ & $\begin{array}{l}\text { Mean } \\
(\mu \mathrm{g} / \mathrm{L})\end{array}$ & $\begin{array}{l}\text { Frequency } \\
(\%)\end{array}$ \\
\hline Fenvalerate & 0.010 & 55 & & \\
\hline Deltamethrin & 0.234 & 100 & & \\
\hline \multicolumn{5}{|l|}{ Organophosphates } \\
\hline Methamidophos & 0.751 & 45 & 0.077 & 55 \\
\hline Ethoprophos & & & 0.028 & 30 \\
\hline Phorate & 0.010 & 5 & 0.10 & 10 \\
\hline Diazinon & 0.012 & 5 & 0.013 & 40 \\
\hline Fonofos & 0.010 & 20 & & \\
\hline Dimethoate & 0.044 & 15 & 0.091 & 25 \\
\hline Pirimiphos-methyl & 0.010 & 15 & 0.010 & 15 \\
\hline Chlorpyrifos & 0.016 & 65 & 0.012 & 50 \\
\hline Malathion & 0.010 & 15 & 0.025 & 10 \\
\hline Fenitrothion & 0.015 & 35 & 0.016 & 20 \\
\hline Parathion & 0.010 & 10 & & \\
\hline Chlorfenvinphos & 0.010 & 5 & 0.064 & 25 \\
\hline Profenofos & 0.010 & 5 & 0.036 & 60 \\
\hline
\end{tabular}

\section{References}

[1] Gordon, C. and Amatekpor, J. K. eds. (1999). The Sustainable integrated development of the Volta Basin in Ghan. Volta Basin Research Publication Vol. I. 58pp

[2] Kalitsi, E. A. K. (1999). The role of Volta River Authority in the development of the Volta Basin. In C. Gordon \& J. K. Amatekpor (Eds), The Sustainable Integrated Development of the Volta Basin in Ghana (pp. 13-24). Accra, Ghana: Gold Type Press.

[3] Brown, C. D., Bellamy, P. H. and Dubus, I. G. (2002).Prediction of pesticide concentrations found in rivers in the United Kingdom. Pest Manage. Sci. 58: 363-373

[4] Mathur, H. B., Johnson, S., Mishra, R., Kumar, A. and Singh, B. (2003). Analysis of pesticide residues in bottled water CSE report, New Delhi, India

[5] Scholtz, T. G, and Flory, D. A. (1999). Clearing up the confusion. Environ .Protect. 10:37- 41.

[6] Petersen, A., Jensen, B. H., Andersen, J. H., Poulsen, M. E., Christensen, T. and Nielsen, E. (2013). Pesticide residuesResults from the period 2004-2011. National Food Institute, Technical University of Denmark. Retrieved from: rapport_overvaagning_pesticider_2004-11\%20(3).pdf

[7] Crawley, M. J. (2007). The R book. John Wiley and Sons Ltd. UK.

[8] United states Environmental Protection Agency (USEPA) (2016). National recommended water quality criteria - Aquatic life criteria table. Retrieved from: https://www.epa.gov/wqc/national-recommended-waterquality-criteria-aquatic-life-criteria-table

[9] Ntow, J. W. (2005). Pesticide Residues in Volta Lake, Ghana, Lakes and Reservoirs: Research and Management, Vol. 10, (4), pp. 243-248. doi:10.1111/j.1440-1770.2005.00278.x.

[10] Darko, G., Akoto, O., and Oppong, C. (2008). Persistent organochlorine pesticide residues in fish, sediments and water from Lake Bosomtwi, Ghana. Chemosphere. 72: 21-24. 
[11] Kuranchie-Mensah, H., Atiemo, M. S., Palm, N. M. L., Blankson-Arthur, S., Osei-Tutu, A., and Fosu, P. (2012). Determination of organochlorine pesticide residue in sediment and water from the Densu River basin, Ghana. Chemosphere 86 (2012): 286-292. Doi:101016/j.chemosphere.2011.10.031.

[12] Agyapong, E. A., Lugushie, J. A., Fei-Baffoe, B. and Atabila, A. (2013). Effect of organochlorine pesticides usage on water quality of Tano River in the Asunafo South District of Brong Ahafo region of Ghana. Pollution Research Journal. 32 (4): 699-706.

[13] Afful, S., Awudza, J. A. M., Osae, S., and Twumasi, S. K. (2013a). Persistent organochlorine compounds in the water and sediment samples from the Lake Bosomtwe in Ghana. American Chemical Science Journal 3(4), 434-448. Retrieved from: file://C:/Users/user/Downloads/1374819375Afful342013ACSj3913\%20(2).pdf. 14/02/14

[14] Ize-Iyamu, O. K.; Asia, I. O. and Egwakhide, P. A. (2007). Concentrations of residues from organochlorine pesticide in water and fish from some rivers in Edo State Nigeria. International Journal of Physical Sciences. 2 (9): 237-241. Retrieved from: http://www.academicjournals.org/article/article1380213547_Iz e-Iyamu $\% 20$ et $\% 20$ al.pdf

[15] Mwevura, H; Othman, O. C. and Mhehe, G. L. (2002). Organochlorine pesticide residues in waters from the coastal area of Dar es Salaam and their effect on aquatic biota. Tanzania Journal of Science. 28 (2): 117-130. Retrieved from: http:/gridnairobi.unep.org/chm/eafdocuments/Tanzania/Orga nochlorine_pesticide.pdf

[16] Mahdavian, S. E. and Somashekar, R. K. (2013) Organochlorine and synthetic pyrethroid pesticides inagricultural soil and water from Chamaranagar district, Karnataka, India. J. Environ. Sci. Water Resourc. 2 (7): 221225 .

[17] Lari, S. Z., Khan, N. A., Gandhi, K. N., Meshram, T. S. and Thacker, N. P. (2014). Comparison of pesticide residues in surface water and ground water of agriculture intensive areas. IJEHSE. 12 (11). DOI: 101.1186/2052-336X-12-11.

[18] Fianko, J. R., Donkor, A., Lowor, S. T., and Yeboah, P. O., (2011). Pesticide residue in water and sediment from the Densu River basin in Ghana. Elixir Pollution 40 (2011)54885492 .

[19] Gitahi, S. M. (1999). Pesticide contamination in Lake Naivasha (Kenya). Conference Paper Vol. 1: Riding the crest into the $21^{\text {st }}$ century. Seatle, WA. DOI: $10.1109 / 1999.799764$. Pages 319-323.

[20] Akan, J. C., Battah, N., Waziri, M. and Mahmud, M. M. (2015). Organochlorine, organophosphorus and pyrethroid pesticides residues in water and sediment samples from River Benue in Vinikilang, Yola, Adamawa State, Nigeria using gas chromatography-mass spectrometry equipped with electron capture detector. American Journal of Environmental Protection, 3 (5): 164-173. DOI: 10.12691/env-3-5-2.

[21] Afful, S., Awudza, J. A. M., Osae, S., and Twumasi, S. K. (2013b). Assessment of synthetic pyrethroids residues in the waters and sediments from the Weija Lake in Ghana. Eur. Chem. Bull. 2(4), 183-187. Retrieved from file://C:/Users/user/Downloads/181-688-1-PB.pdf.14/02/14

[22] Fosu-Mensah, B. Y., Okoffo, E. D. and Mensah, M. (2016). Synthetic pyrethroids pesticide residues in soils and drinking water sources from cocoa farms in Ghana. Environment and Pollution; 5 (1). 60-72. doi: 10.5539/ep.v5n1p60. 